\title{
Facing the First-line in Metastatic Non-small-cell Lung Cancer - Immunotherapy and Chemotherapy
}

\begin{abstract}
Alessandro De Toma, Giuseppe Lo Russo, Diego Signorelli, Roberto Ferrara, Arsela Prelaj, Giulia Galli, Giuseppe Viscardi, Benedetta Trevian Monica Ganzinelli, Nicoletta Zilembo, Filippo de Braud, Marina Chiara Garassino and Claudia Proto
\end{abstract}

Department of Medical Oncology, Fondazione IRCCS Istituto Nazionale dei Tumori, Milan, Italy

DOI: https://doi.org/10.17925/EOH.2020.16.1.39

O ver the last few years, the treatment of metastatic non-small-cell lung cancer (NSCLC) has completely changed due to the advent of immunotherapy, which dramatically improved prognosis in patients without any driver alterations. First, three distinct immune checkpoint inhibitors (ICIS), nivolumab, pembrolizumab and atezolizumab, became the standard second- or later-line treatments in both squamous and non-squamous NSCLC; later pembrolizumab replaced first-line chemotherapy in advanced NSCLC characterised by programmed death ligand 1 expression of at least $50 \%$. Based on the significant efficacy and safety results using single-agent immunotherapy, ICIs in combination with other ICIs or chemotherapy, have been largely evaluated. In particular, since 2018, several studies combining ICls and platinum-based chemotherapy as first-line treatment showed impressive results quickly resulting in a promising new standard of care for the near future.

\section{Keywords}

NSCLC, chemotherapy, immunotherapy, atezolizumab, pembrolizumab, first-line treatment

Disclosures: Giuseppe Lo Russo declares travel, accommodations and honoraria from AstraZeneca, MSD International GmbH, BMS and Eli Lilly. Diego Signorelli declares travel, accommodations and honoraria from AstraZeneca, MSD International GmbH and BMS. Filippo de Braud provided consultation, attended advisory boards and/or provided lectures for the following organizations, from whom he received honoraria or educational grants: Amgen, AstraZeneca, Boehringer-Ingelheim, BMS, Eli Lilly, F Hoffmann-La Roche, Ignyta, Merck Sharp and Dohme, Merck Serono, Novartis and Pfizer. Marina Chiara Garassino declares personal financial interests with the following organisations: AstraZeneca, MSD International GmbH, BMS, Boehringer Ingelheim Italia SpA, Celgene, Eli Lilly, Ignyta, Incyte, Inivata, Medımmune, Novartis, Pfizer, Roche and Takeda; she also declares institutional financial interests with the following organizations: Eli Lilly, MSD, Pfizer (MISP), AstraZeneca, MSD International GmbH, BMS, Boehringer Ingelheim Italia SpA, Celgene, Ignyta, Incyte, Inivata, MedImmune, Novartis, Pfizer, Roche Takeda, Tiziana and Foundation Medicine; and she has received research funding from the following organisations: AIRC, AIFA, Italian MOH, TRANSCAN. Claudia Proto declares travel, accommodations and honoraria from MSD International GmbH, BMS and Eli Lilly. Alessandro De Toma, Roberto Ferrara, Arsela Prelaj, Giulia Galli, Giuseppe Viscardi, Benedetta Trevian, Monica Ganzinelli and Nicoletta Zilembo have no financial or non-financial relationships or activities to declare in relation to this article.

Review Process: Double-blind peer review.

Compliance with Ethics: This article involves a review of the literature and does not report on new clinical data, or any studies with human or animal subjects performed by any of the authors.

Authorship: All named authors meet the International Committee of Medical Journal Editors (ICMJE) criteria for authorship of this manuscript, take responsibility for the integrity of the work as a whole and have given final approval for the version to be published.

Access: This article is freely accessible at touchONCOLOGY.com (C) Touch Medical Media 2020.

Received: 11 October 2019

Accepted: 19 February 2020

Published Online: 1 September 2020

Citation: European Oncology \& Haematology. 2020;16(1):39-43

Corresponding Author: Alessandro De Toma, Department of Medical Oncology, Fondazione IRCCS Istituto Nazionale dei Tumori, Via Giacomo Venezian 1, 20133, Milan, Italy. E: alessandro.detoma@istitutotumori.mi.it

Support: No funding was received in the publication of this article.
Historically, chemotherapy represented the only available treatment for patients with advanced non-small-cell lung cancer (NSCLC) who did not show any target molecular driver, such as epidermal growth factor receptor (EGFR), anaplastic lymphoma kinase (ALK) or the receptor tyrosine kinase ROS1. Unfortunately, limited efficacy was reported using chemotherapy alone. ${ }^{1}$ The advent of immunotherapy, a treatment based on immune system activation in order to destroy tumour cells, ${ }^{2}$ has radically changed the therapeutic scenario for these patients. The immune checkpoint inhibitors (ICIS) that showed activity in NSCLC are monoclonal antibodies (mAbs) directed against programmed cell death protein 1 (PD-1), its ligand (programmed death-ligand 1 [PD-L1]), or cytotoxic T-lymphocyte-associated-4 (CTLA-4); all molecules involved in cancer cell immune evasion (PD-1, PD-L1 and CTLA-4). ${ }^{3}$ ICls cause an activation of immune response against cancer cells by blocking the inhibitory regulation of these cellular pathways. ${ }^{2}$

Initially, ICls were compared with standard chemotherapy in pre-treated NSCLC showing their superiority in terms of both efficacy and safety. ${ }^{4-7}$ According to these data, two mAbs directed against PD-1, nivolumab and pembrolizumab, and one mAb against PD-L1, atezolizumab, achieved approval as second- or later-line treatment in NSCLC, irrespective of PD-L1 expression for nivolumab and atezolizumab, and in PD-L1 1 1\% NSCLC for pembrolizumab. Secondly, based on a significant benefit in patients with PD-L1 $\geq 50 \%$ NSCLC in the phase I study KEYNOTE-001, ${ }^{8}$ pembrolizumab was successfully compared with standard platinum-based chemotherapy in the phase II study KEYNOTE-024, ${ }^{9}$ soon becoming the new standard first-line treatment for patients with NSCLC with a PD-L1 expression of at least $50 \%$. The advantage over first-line chemotherapy in PD-L1 $\geq 50 \%$ NSCLC was further confirmed in the KEYNOTE-042 study, which enrolled patients with $\mathrm{PD}-\mathrm{L} 1 \geq 1 \%{ }^{10}$

Based on the impressive data using ICl monotherapy, since 2018 several studies have evaluated $\mathrm{ICl}$ combinations (pembrolizumab and atezolizumab, in particular) alongside standard chemotherapy in treatment-naïve NSCLC, showing again significant advantages compared with standard therapy. ${ }^{11-17}$ To date, the best first-line treatment out of all the available options, and adequate patient selection, still remains an issue. In this review we will report the results of trials evaluating the association between chemotherapy and ICIS as first-line treatment in advanced 
Table 1: Results from randomised clinical trials comparing the association of chemotherapy with immunotherapy over chemotherapy alone

\begin{tabular}{|c|c|c|c|c|c|c|c|c|c|}
\hline Study & Histology & $\begin{array}{l}\text { Number } \\
\text { of } \\
\text { patients }\end{array}$ & Treatment arms & $\begin{array}{l}\text { Crossover } \\
\text { rate } \%\end{array}$ & $\begin{array}{l}\text { Overall } \\
\text { survival }\end{array}$ & $\begin{array}{l}\text { Progression-free } \\
\text { survival }\end{array}$ & $\begin{array}{l}\text { Objective } \\
\text { response } \\
\text { rate }\end{array}$ & $\begin{array}{l}\text { Grade } \\
3-5 \text { AEs }\end{array}$ & $\begin{array}{l}\text { Other } \\
\text { endpoints }\end{array}$ \\
\hline KEYNOTE-18912 & Nsq & 616 & $\begin{array}{l}\text { Pembrolizumab + platin } \\
+ \text { pemetrexed } \\
\text { versus } \\
\text { platin + pemetrexed }\end{array}$ & $41.3 \%$ & $\begin{array}{l}\text { NR versus } \\
11.3 \text { months } \\
\text { HR } 0.49 \\
p<0.001\end{array}$ & $\begin{array}{l}8.8 \text { versus } \\
4.9 \text { months } \\
\text { HR } 0.52 \\
p<0.001\end{array}$ & $\begin{array}{l}47.6 \% \\
\text { versus } \\
18.9 \% \\
p<0.001\end{array}$ & $\begin{array}{l}67.2 \% \\
\text { versus } \\
65.8 \%\end{array}$ & $\begin{array}{l}\text { DoR: } \\
11.2 \text { versus } \\
7.8 \text { months }\end{array}$ \\
\hline KEYNOTE-02111,30 & Nsq & 123 & $\begin{array}{l}\text { Pembrolizumab + carboplatin } \\
+ \text { pemetrexed } \\
\text { versus } \\
\text { carboplatin + pemetrexed }\end{array}$ & $46.4 \%$ & $\begin{array}{l}\text { NR versus } \\
21.1 \text { months } \\
\text { HR } 0.56 \\
p=0.0151\end{array}$ & $\begin{array}{l}24.0 \text { versus } \\
9.3 \text { months } \\
\text { HR } 0.53 \\
p=0.0049\end{array}$ & $\begin{array}{l}56.7 \% \\
\text { versus } \\
30.2 \% \\
p=0.0016\end{array}$ & $\begin{array}{l}40.7 \% \\
\text { versus } \\
27.4 \%\end{array}$ & $\begin{array}{l}\text { Not } \\
\text { reported }\end{array}$ \\
\hline IMpower132 ${ }^{13}$ & Nsq & 578 & $\begin{array}{l}\text { Atezolizumab + platin } \\
+ \text { pemetrexed } \\
\text { versus } \\
\text { platin + pemetrexed }\end{array}$ & $\begin{array}{l}\text { Not } \\
\text { allowed }\end{array}$ & $\begin{array}{l}18.1 \text { versus } \\
13.6 \text { months } \\
\text { HR } 0.46\end{array}$ & $\begin{array}{l}7.6 \text { versus } \\
5.2 \text { months } \\
\text { HR } 0.6 \\
p<0.0001\end{array}$ & $\begin{array}{l}\text { Not } \\
\text { reported }\end{array}$ & $\begin{array}{l}54 \% \\
\text { versus } \\
39 \%\end{array}$ & $\begin{array}{l}\text { Not } \\
\text { reported }\end{array}$ \\
\hline IMpower13014 & Nsq & 724 & $\begin{array}{l}\text { Atezolizumab + carboplatin } \\
+ \text { nab-paclitaxel } \\
\text { versus } \\
\text { carboplatin + nab-placitaxel }\end{array}$ & $41 \%$ & $\begin{array}{l}18.6 \text { versus } \\
13.9 \text { months } \\
\text { HR } 0.79 \\
p=0.033\end{array}$ & $\begin{array}{l}7.0 \text { versus } \\
5.5 \text { months } \\
\text { HR } 0.64 \\
p<0.0001\end{array}$ & $\begin{array}{l}\text { Not } \\
\text { reported }\end{array}$ & $\begin{array}{l}73.2 \% \\
\text { versus } \\
60.3 \%\end{array}$ & $\begin{array}{l}\text { Not } \\
\text { reported }\end{array}$ \\
\hline IMpower15015 & Nsq & 1,202 & $\begin{array}{l}\text { Atezolizumab + bevacizumab } \\
+ \text { carboplatin + paclitaxel } \\
\text { versus } \\
\text { bevacizumab + carboplatin } \\
\text { + paclitaxel }\end{array}$ & $\begin{array}{l}\text { Not } \\
\text { allowed }\end{array}$ & $\begin{array}{l}19.2 \text { versus } \\
14.7 \text { months } \\
\text { HR } 0.78 \\
p=0.02\end{array}$ & $\begin{array}{l}8.3 \text { versus } \\
6.8 \text { months } \\
\text { HR } 0.62 \\
p<0.001\end{array}$ & $\begin{array}{l}63.5 \% \\
\text { versus } \\
48.0 \%\end{array}$ & $\begin{array}{l}58.5 \% \\
\text { versus } \\
50.0 \%\end{array}$ & $\begin{array}{l}\text { DoR: } \\
9.0 \text { versus } \\
5.7 \text { months }\end{array}$ \\
\hline KEYNOTE-40716 & $\mathrm{Sq}$ & 559 & $\begin{array}{l}\text { Pembrolizumab + carboplatin } \\
\text { + paclitaxel/nab-paclitaxel } \\
\text { versus } \\
\text { carboplatin + paclitaxel/ } \\
\text { nab-paclitaxel }\end{array}$ & $32 \%$ & $\begin{array}{l}15.9 \text { versus } \\
11.3 \text { months } \\
\text { HR } 0.64 \\
p<0.001\end{array}$ & $\begin{array}{l}6.4 \text { versus } \\
4.8 \text { months } \\
\text { HR } 0.56 \\
p<0.001\end{array}$ & $\begin{array}{l}58.4 \% \\
\text { versus } \\
35.0 \%\end{array}$ & $\begin{array}{l}69.8 \% \\
\text { versus } \\
68.2 \%\end{array}$ & $\begin{array}{l}\text { DoR: } \\
7.7 \text { versus } \\
4.8 \text { months }\end{array}$ \\
\hline IMpower13117,38 & $\mathrm{Sq}$ & 1,021 & $\begin{array}{l}\text { Atezolizumab + carboplatin } \\
+ \text { nab-paclitaxel } \\
\text { versus } \\
\text { carboplatin + nab-paclitaxel }\end{array}$ & $43 \%$ & $\begin{array}{l}14.0 \text { versus } \\
13.9 \text { months } \\
\text { HR } 0.96\end{array}$ & $\begin{array}{l}6.3 \text { versus } \\
5.6 \text { months } \\
\text { HR } 0.71 \\
p<0.0001\end{array}$ & $\begin{array}{l}\text { Not } \\
\text { reported }\end{array}$ & $\begin{array}{l}69 \% \\
\text { versus } \\
58 \%\end{array}$ & $\begin{array}{l}\text { Not } \\
\text { reported }\end{array}$ \\
\hline
\end{tabular}

AES = adverse events; $D O R=$ duration of response; $H R=$ hazard ratio; $N R=$ not reached; $N s q=$ non-squamous; $S q=$ squamous.

NSCLC, underlining the strengths and weaknesses of each study. Our aim is to help clinicians determine the best therapeutic strategy.

\section{Chemotherapy plus immunotherapy - the rationale}

To date, in advanced NSCLC without driver alterations, PD-L1 represents the only clinically used biomarker to select the best first-line therapy, allowing access to first-line pembrolizumab monotherapy only to NSCLC patients with PD-L1 $\geq 50 \%$.9.10 However, despite a higher likelihood of response with a higher PD-L1 expression, ${ }^{8-10}$ a small percentage of patients with NSCLC with lower PD-L1 expression have benefitted from $\mathrm{ICl}$ treatment. ${ }^{10}$ On the other hand, several groups have reported that a variable percentage (14-26\%) of patients with NSCLC experienced rapid tumour growth acceleration when treated with immunotherapy compared with chemotherapy, irrespective of the PD-L1 level, the so-called 'hyperprogressive disease'. ${ }^{18-20}$ To better select patients for immunotherapy, other biomarkers, such as tumour mutational burden (TMB), have been carefully investigated but the results still remain debatable. ${ }^{21}$ Meanwhile, the addition of chemotherapy to immunotherapy has developed as an alternative strategy to extend ICls to a larger population, regardless of PD-L1 status.

Chemotherapy has myelosuppressive effects due to the cytotoxicity of each single agent, with the potential ability to deplete the immune cells involved in the antitumor response. However, combining chemotherapy with ICIs has antitumor effects that may favour immune system activity. Chemotherapy can induce immunogenic cell death, a non-physiological cell death associated with the release of danger-associated molecular patterns and tumour antigens; ${ }^{21-23}$ the consequence is the activation of antigen-presenting cells and lymphocyte T-cells. ${ }^{24}$ Chemotherapy can stop cancer's escape from immune response; moreover, it can enhance antigen presentation, ${ }^{25}$ promote PD-L1 expression on cancer cells, ${ }^{26}$ exhaust the myeloid-derived suppressor cells ${ }^{23,27}$ and reduce T-regulatory cells. ${ }^{28}$ Based on this, several studies are leading to an increased understanding of the real value of chemotherapy and immunotherapy combinations in NSCLC (Table 1).

\section{Chemotherapy plus immunotherapy - non-squamous non-small-cell lung cancer KEYNOTE-021}

KEYNOTE-021 was the first study to demonstrate the safety and efficacy of a PD-1 inhibitor in combination with chemotherapy in locally advanced or metastatic NSCLC.1 In cohort G of this study, untreated patients with advanced non-squamous NSCLC, with no EGFR or ALK alterations, were randomised 1:1 to receive standard chemotherapy (carboplatin plus pemetrexed) with or without pembrolizumab, irrespective of PD-L1 status. As already reported in previous analyses, ${ }^{11,29}$ after a follow-up of around 2 years, the combination of pembrolizumab and chemotherapy showed a 
significant advantage compared with chemotherapy alone. Median overall survival (OS) was not reached in the experimental arm versus 21.1 months in the control arm (hazard ratio [HR] 0.56; 95\% confidence interval [Cl] $0.32-0.95 ; p=0.0151$ ), with a benefit in objective response rate (ORR) of $24.6 \%$ (56.7\% versus 30.2\%; 95\% Cl 8.9-42.4\%; $\mathrm{p}=0.0016$ ) and a benefit in progression-free survival (PFS) of over 14 months (24.0 versus 9.3 months; HR 0.53; 95\% Cl 0.33-0.89; $p=0.0049$ ). ${ }^{30}$

A recent exploratory analysis of KEYNOTE-021 evaluated the association between TMB and outcomes. Seventy patients with available tissue were included in the TMB analysis (12/24 treated with carboplatin and pemetrexed in cohort C, 32/60 of the pembrolizumab plus chemotherapy arm, and 26/63 of the chemotherapy alone arm in cohort G). TMB, as a continuous variable, was not significantly associated with OS, PFS or ORR for either pembrolizumab plus chemotherapy or chemotherapy alone. No association between TMB and PD-L1 expression was reported in patients treated with the combination. ${ }^{31}$

\section{KEYNOTE-189}

KEYNOTE-189 was the first phase III study confirming the significant advantages of chemotherapy plus immunotherapy in combination as first-line treatment in non-squamous NSCLC.12 In this study, patients with metastatic non-squamous NSCLC, were randomly assigned in a 2:1 ratio to receive standard chemotherapy (cisplatin or carboplatin and pemetrexed) plus pembrolizumab or placebo irrespective of PD-L1 status. Patients with EGFR mutations or ALK rearrangements were excluded, as well as patients with uncontrolled brain metastases. Those with previously treated or asymptomatic brain metastases were included. Coprimary endpoints were OS and PFS. Median OS was not reached in the experimental arm, while in the placebo arm was 11.3 months (HR 0.49 ; $p<0.001$ ); patients alive at 12 months were $69.2 \%$ versus $49.4 \%$ in the experimental and in placebo arm, respectively. The benefit was consistent across all subgroups, irrespective of PD-L1 expression; however, a positive trend with the increase of PD-L1 was reported. In addition, the combination obtained better results in terms of PFS, than chemotherapy alone, with a median PFS of 8.8 versus 4.9 months (HR $0.52 ; p<0.001$ ), and a consistent benefit in all subgroups. The combination group also showed its superiority in other endpoints with an ORR of $47.6 \%$ versus $18.9 \%(p<0.001)$, and a median duration of response of 11.2 versus 7.8 months in the combination group versus the control group, respectively. Finally, the safety profile was manageable in the experimental arm, with no markedly higher incidence of adverse events (AEs) except for acute kidney injury that was of grade 3 or higher in $2 \%$ of patients (note that both cisplatin and pemetrexed are nephrotoxic drugs); the frequency of treatment-related grade $3 / 4$ toxicities was of $67.2 \%$ versus $65.8 \%$, in the combination versus placebo arm, respectively.

In a subsequent exploratory analysis both OS and PFS in patients with liver metastases were superior in the combination arm versus placebo: median OS was 12.6 versus 6.6 months (HR 0.62), and median PFS was 6.1 versus 3.4 months (HR 0.52). Moreover, the combination showed its benefit over chemotherapy in patients with brain metastases, with an OS of 19.2 versus 7.5 months (HR 0.41) and a PFS of 6.9 versus 4.7 months (HR 0.42), respectively. ${ }^{32}$ After a median follow-up of almost 2 years, updated results confirmed a benefit: median OS was 22.6 months in the experimental arm and 10.7 months in the control arm, with a 1-year survival of $70 \%$ versus $48 \%$. The magnitude of OS benefit assessed by HR was similar across subgroups defined by the PD-L1 level, including PD-L1-negative tumours. ${ }^{33}$

The association of TMB with outcomes in the KEYNOTE-189 trial has been presented. ${ }^{34}$ Considering the 293 evaluable patients with NSCLC, including 207 treated with the combination and 86 with chemotherapy alone, TMB was again not significantly associated with the efficacy of either pembrolizumab plus chemotherapy or chemotherapy alone. Even in this analysis, no association between TMB and PD-L1 expression in the combination ( $p=0.27$ ) or the chemotherapy subgroup ( $p=0.92$ ) was found. Finally, using a cut-off of 175 mutations per exome to distinguish patients with TMB-high $(n=134)$ or TMB-low $(n=159)$ tumours, OS, PFS and ORR were similar in patients with TMB-high and TMB-low tumours, both in the experimental and the control arm.

\section{IMpower132}

The phase III IMpower132 compared the addition of atezolizumab to the same platinum-based standard chemotherapy versus chemotherapy alone as first-line treatment in advanced non-squamous NSCLC without EGFR and ALK alterations and untreated brain metastases..$^{13}$ OS and PFS were coprimary endpoints. Similar to pembrolizumab, the addition of atezolizumab to chemotherapy resulted in a better PFS ( 7.6 versus 5.2 months; HR 0.6; 95\% Cl 0.49-0.72; $p<0.0001$ ). The benefit was evident across all subgroups, irrespective of smoking history, with a positive trend in patients who had never smoked, and of PD-L1 status, with better results among patients with higher PD-L1 expression. However, PD-L1 status was not available in all patients and all subgroup analyses were purely exploratory; therefore, the data do not have any statistical relevance. Although data are not mature yet, the combination group is also superior in terms of OS, with a benefit of 4.5 months over chemotherapy alone (18.1 versus 13.6 months, HR 0.46). In relation to AEs, atezolizumab plus chemotherapy was manageable with $54 \%$ versus $39 \%$ of grade $3 / 4$ toxicity compared with chemotherapy alone, and $15 \%$ of AEs leading to withdrawal of atezolizumab; no new safety signals emerged.

\section{IMpower130}

Atezolizumab plus chemotherapy was evaluated in non-squamous NSCLC in another phase III trial, IMpower130. ${ }^{14}$ Patients with untreated non-squamous NSCLC were randomised 2:1 to receive carboplatin plus nab-paclitaxel with or without atezolizumab. Unlike previously reported studies, in this trial, patients with EGFR or ALK alterations were included, after a previous target therapy. The combination arm ensured an OS benefit of 4.7 months compared with the chemotherapy group (18.6 versus 13.9 months, respectively; HR $0.79 ; 95 \% \mathrm{Cl} 0.64-0.98 ; \mathrm{p}=0.033$ ), with a rate of patients alive at 1 year of $63.1 \%$ versus $55.5 \%$, respectively, and a statistically significant benefit in PFS (7.0 versus 5.5 months; HR 0.64; $95 \% \mathrm{Cl} 0.54-0.77 ; \mathrm{p}<0.0001)$. Benefit in OS and PFS was consistent in all subgroups with the exception of patients with target alterations (EGFR/ $A L K)$ or with liver metastases. The benefit was consistent independently of PD-L1 status. Treatment-related AEs grade $3 / 4$ occurred in $73.2 \%$ in the atezolizumab-chemotherapy group and in $60.3 \%$ in the chemotherapy alone group, while treatment discontinuation was reported in $26 \%$ versus $22 \%$ of patients, respectively.

\section{IMpower150}

Finally, in non-squamous histology, atezolizumab was evaluated in combination with the antiangiogenic agent, bevacizumab, and chemotherapy. In IMpower150, ${ }^{15}$ treatment-naive patients with metastatic non-squamous NSCLC were randomly assigned (1:1:1) to receive carboplatin-paclitaxel chemotherapy plus bevacizumab with or without atezolizumab, or carboplatin-paclitaxel plus atezolizumab, irrespective of PD-L1, EGFR or ALK status. For patients with EGFR or ALK alterations, it was mandatory to be treated with at least a tyrosine-kinase inhibitor. Coprimary endpoints were OS in the wild-type (WT) population and PFS in both the WT population and in the WT population with a high expression of an effector T-cell gene signature (around $43 \%$ of the intention to treat population [ITT]). 
In the comparison of chemotherapy plus bevacizumab with or without atezolizumab, PFS was extended in the experimental arm, with a median of 8.3 versus 6.8 months (HR 0.62; 95\% $\mathrm{Cl} 0.52-0.74 ; \mathrm{p}<0.001$ ) across the all-WT population and with a further benefit in the effector T cell-high population (11.3 versus 6.8 months; HR 0.51; 95\% Cl 0.38-0.68; $p<0.001$ ). PFS benefit was seen in all subgroups, including patients with EGFR or ALK alterations (9.7 versus 6.1 months; HR 0.59; 95\% Cl 0.37-0.94) and irrespective of PD-L1 status (with a trend towards a higher benefit in PD-L1 $250 \%$ ). Moreover, the association of bevacizumab plus atezolizumab with chemotherapy showed a better PFS in patients with liver metastases (7.4 versus 4.9 months; HR 0.42; $95 \% \mathrm{Cl} 0.26-0.76$ ), a population usually characterised by worse prognosis. ${ }^{35,36} \mathrm{At}$ the interim analysis, atezolizumab and bevacizumab plus chemotherapy resulted in a better outcome in the ITT WT population with a median OS of 19.2 versus 14.7 months (HR 0.78; $95 \% \mathrm{Cl} 0.64-0.96 ; \mathrm{p}=0.02)$. AEs were consistent with known toxicities of the drugs: grade $3 / 4$ treatment-related AEs were reported in $60 \%$ versus $51 \%$ of patients in the atezolizumab, bevacizumab and carboplatin-paclitaxel group versus the bevacizumab and carboplatin-paclitaxel arm, and AES leading to treatment discontinuation in 34\% versus $25 \%$, respectively. ${ }^{15}$

Recently, a meta-analysis reported data of the combination of atezolizumab and chemotherapy as first-line treatment in 152 patients with non-squamous NSCLC with EGFR or ALK alterations (IMpower150 and 130): the combination was superior over chemotherapy alone in these patients (PFS HR 0.62). This result supports the use of this combination in patients with driver alterations. ${ }^{37}$

\section{Chemotherapy plus immunotherapy - squamous non-small-cell lung cancer KEYNOTE-407}

In squamous histology, the combination of chemotherapy plus immunotherapy has shown important results. In the phase III study, KEYNOTE-407, patients with advanced, never-treated squamous NSCLC patients were randomised 1:1 to receive chemotherapy (carboplatin with paclitaxel or nab-paclitaxel) with or without pembrolizumab. ${ }^{16}$ OS and PFS were coprimary endpoints. After a median follow-up of 7.8 months, the experimental arm was better than chemotherapy alone, with a median OS of 15.9 versus 11.3 months (HR 0.64; 95\% Cl 0.49-0.85; $\mathrm{p}=0.0008)$ and a difference in survival rate at 1 year of $16.9 \%(65.2 \%$ versus 48.3\%). The benefit in OS was irrespective of PD-L1 status with no significant differences according to the PD-L1 expression level. The combination also resulted in improved PFS, showing a median PFS of 6.4 versus 4.8 months (HR $0.56 ; 95 \% \mathrm{Cl} 0.45-0.7 ; \mathrm{p}<0.001$ ), the benefit was again consistent across all subgroups with a trend towards a higher benefit in those patients with higher PD-L1 expression. An advantage in ORR of $23.4 \%$ (58.4\% versus $35.0 \%, p=0.0004)$ was also reported in the experimental arm. The toxicity profile of the combination was similar to that of the chemotherapy alone: grade 3 or higher AEs were reported in $69.8 \%$ versus $68.2 \%$, while the percentages of all-treatment discontinuation were $13 \%$ versus $6 \%$, respectively.

\section{IMpower131}

In another phase III study, IMpower131, ${ }^{17}$ treatment-naïve patients with advanced squamous NSCLC, were randomly assigned to receive chemotherapy (carboplatin and nab-paclitaxel or paclitaxel), with or without atezolizumab. PFS and OS were coprimary endpoints. Results of the third arm, including paclitaxel, are not available yet. In the comparison between carboplatin-nab-paclitaxel plus atezolizumab versus chemotherapy alone, patients reported a benefit in PFS in the experimental arm, with a median PFS of 6.3 versus 5.6 months (HR 0.71 ; $95 \% \mathrm{Cl} 0.6-0.85 ; \mathrm{p}=0.0001$ ) and a PFS rate at 1 year of $24.7 \%$ versus $12.0 \%$.
In the subgroup analysis, a benefit was present across all subgroups, including patients with liver metastases and regardless of PD-L1 status, with a higher benefit in patients with higher PD-L1 expression; however, this analysis was not planned to demonstrate any statistical significance.

Unexpectedly, this was the first formally negative study: OS, the second coprimary endpoint, was negative at the first interim analysis, with a median OS of 14 months for atezolizumab plus chemotherapy and 13.9 months for chemotherapy alone. AEs were consistent with known safety risks and generally manageable, with a limited increase in grade $3 / 4$ toxicity in the combination treatment ( $69 \%$ versus $58 \%$ ). More recently, the final analysis confirmed previous results, in that the association of chemotherapy and immunotherapy did not demonstrate any benefit in OS in the overall population. Only in PD-L1 $\geq 50 \%$ patients, median OS was significantly superior with the combination compared with chemotherapy alone (23.4 versus 10.2 months; HR 0.48; 95\% Cl 0.29-0.81). ${ }^{38}$

\section{Critical analysis and conclusions}

Single-agent immunotherapy has dramatically changed treatment and prognosis in patients with NSCLC without any target alterations, firstly by becoming the standard therapy in pre-treated patients, then the best first-line treatment choice in selected cases (PD-L1 $\geq 50 \%$ ). Recently, a second revolution affected therapy in NSCLC, with the development of $\mathrm{ICl}$ combination with standard chemotherapy; a new strategy that it is going to define a new therapeutic algorithm worldwide. Several phase III studies have reported significant advantages with the combination both in squamous and non-squamous histology, showing a benefit in patients with lower PD-L1 expression. 13-16,34,37 Recently, a pooled analysis of 428 patients with PD-L1-negative NSCLC treated with the combination of pembrolizumab and chemotherapy in KEYNOTE-407, KEYNOTE-189 and KEYNOTE-021, confirmed the advantage of the combination over chemotherapy alone: OS was 19 versus 11 months, ORR $46.9 \%$ versus $28.6 \%$, and PFS 6.5 versus 5.4 months, respectively. ${ }^{39}$

In general, the available data support the use of the combination of chemotherapy plus immunotherapy as standard first-line treatment in all-comers. However, the most appropriate choice of first-line treatment should be assessed on a case-by-case basis. The strategy of combining chemotherapy with ICIs also opens the door for immunotherapy patients with NSCLC with lower PD-L1 expression (PD-L1 <50\%). In this subgroup, the addition of chemotherapy may be useful favouring the immune system activity. On the other hand, clinicians now have to choose between two distinct first-line alternatives in subjects with PD-L1 $150 \%$, where single-agent pembrolizumab has already been approved as the new standard. To date, no comparison between the two options exists and it probably never will. Surely, based on its synergistic effects, the addition of chemotherapy may potentially improve the outcomes of ICls also in patients with PD-L1 $250 \%$.

Nevertheless, although the safety profile of combinations is generally considered manageable, the impact of chemotherapy on the toxicity of first-line treatment is an important point to define the best therapeutic strategy in patients with PD-L1 $\geq 50 \%$ NSCLC. This subgroup has a high likelihood of achieving significant and durable response using the commonly well-tolerated pembrolizumab alone, and the long-term benefit with combinations compared to a single agent is still debatable. Moreover, immune-related AEs due to ICIS are not prevented by the addition of chemotherapy. Otherwise, the combination may reduce the rate of early disease progression documented in many single-agent immunotherapy trials. Finally, considering the predictive biomarkers of ICI activity, PD-L1 expression and TMB, their role is significantly attenuated with the addition 
of chemotherapy: neither PD-L1 nor TMB appear predictive of benefit in OS in the previously reported combination trials. According to these data, the strategy in this subgroup with higher PD-L1 is not defined but has to be evaluated on the basis of single patient characteristics (age, clinical condition, PD-L1 level, other biomolecular aspects).

To further extend the use of immunotherapy, its combination to the standard treatment was also evaluated in NSCLC with target alterations. In EGFR-mutant disease, durvalumab was combined with osimertinib in the phase Ib TATTON study, ${ }^{40}$ and nivolumab with erlotinib in another phase I study, ${ }^{41}$ whilst atezolizumab has been combined with erlotinib, ${ }^{42}$ and durvalumab with gefitinib. ${ }^{43}$ Unfortunately, in all of these studies, a high rate of grade $3 / 4$ AEs were reported. Also, in patients with $A L K$-rearrangement, the combinations of nivolumab plus crizotinib44 and ceritinib plus nivolumab ${ }^{45}$ were too toxic with high incidences of grade 3/4 AEs. In contrast, the combinations of atezolizumab plus alectinib ${ }^{46}$ and Iorlatinib plus avelumab ${ }^{47}$ seemed well tolerated. Further studies are needed.

Recently, the combination of an $\mathrm{ICl}$ with another $\mathrm{ICl}$ has achieved interesting results. Following the phase I CheckMate 012 trial, ${ }^{48}$ the phase III CheckMate 227 trial randomised untreated patients with advanced squamous and non-squamous NSCLC according to PD-L1 status (positive versus negative) to receive either nivolumab alone or in combination with chemotherapy or the combination of nivolumab plus ipilimumab. ${ }^{49}$ In patients characterised by a high TMB level (TMB $\geq 10$ mutations/Mb), the combination of nivolumab plus ipilimumab showed better outcomes in terms of PFS, irrespective of the PD-L1 status, and OS benefit was independent of the TMB level. In CheckMate 227, the combination of nivolumab plus chemotherapy was also evaluated in patients with NSCLC with no PD-L1 expression, achieving a benefit in ORR of $>10 \%$ in comparison with the combination of nivolumab plus ipilimumab (37.9\% versus $27.3 \%$, respectively), but both duration of response (18.0 versus 8.3 months, respectively) and OS (OS at 2 years $40.4 \%$ versus $34.7 \%$, respectively) were superior for the ICI combination over chemotherapy plus nivolumab association. ${ }^{50}$

Currently, according to these exciting results, chemotherapy and immunotherapy have already been introduced into clinical practice as first-line therapy, changing the therapeutic algorithm in NSCLC again. However, better patient selection with treatment personalisation still represents a challenge.
1. National Comprehensive Cancer Network (NCCN). NCCN clinical practice guidelines in oncology: non-small cell lung cancer. Version 3. 2020. Available at: www.nccn.org/ professionals/physician_gls/pdf/nscl.pdf (accessed: 27 February 2020).

2. Pardoll DM. The blockade of immune checkpoints in cancer immunotherapy. Nat Rev Cancer. 2012;12:252-64.

3. Thompson RH, Gillett MD, Cheville JC, et al. Costimulatory $\mathrm{B} 7-\mathrm{H} 1$ in renal cell carcinoma patients: indicator of tumor aggressiveness and potential therapeutic target. Proc Natl Acad SCi USA. 2004;101:17174-9.

4. Brahmer J, Reckamp KL, Baas P, et al. Nivolumab versus docetaxel in advanced squamous-cell non-small-cell lung cancer. N Eng/ I Med. 2015;373:123-35.

5. Borghaei H, Paz-Ares L, Horn L. Nivolumab versus docetaxel in advanced squamous-cell non-small-cell lung cancer. N Engl J Med. 2015;373:1627-39.

6. Rittmeyer A, Barlesi F, Waterkamp D, et al. Atezolizumab versus docetaxel in patients with previously treated non-small-cell lung cancer (OAK): a phase 3, open-label, multicentre lung cancer (OAK). a phase 3, open-label, multicentre

7. Herbst RS, Baas P, Kim DW, et al. Pembrolizumab versus docetaxel for previously treated, PD-L1-positive, advanced docetaxel for previously treated, PD-L1-positive, advanced
non-small-cell lung cancer (KEYNOTE-010): a randomised non-small-cell lung cancer (KEYNOTE-010):

8. Garon EB, Rizvi NA, Hui R, et al. Pembrolizumab for the treatment of non-small-cell lug cancer. N Eng J Med. 2015;372:2018-28.

9. Reck M, Rodriquez-Abreu D, Robinson AG, et al. Pembrolizumab versus chemotherapy for PD-L1-positive non-small-cell lung cancer. N Eng/ J Med. 2016;375:1823-33.

10. Mok TSK, Wu YL, Kudaba I, et al. Pembrolizumab versus chemotherapy for previously untreated, PD-L1 expressing locally advanced or metastatic non-small cell lung cance (KEYNOTE-042): a randomized, open-label, controlled, phase (KEYNOTE-042): a randomized, open
trial. Lancet. 2019:393:1819-30.

11. Langer CJ, Gadgeel SM, Borghaei $\mathrm{H}$, et al. Carboplatin and pemetrexed with or without pembrolizumab for advanced, non-squamous non-small-cell lung cancer: a randomised, phase 2 cohort of the open-label KEYNOTE-021 study. Lancet Oncol 2016:17:1497-508.

12. Gandhi L, Rodríguez-Abreu D, Gadgeel S, et al. Pembrolizumab plus chemotherapy in metastatic non-small-cell lung cancer. N Eng/ J Med. 2018;378:2078-92.

13. Papadimitrakopoulou V, Cobo M, Bordoni R, et al. OA05.07 IMpower132: PFS and safety results with $1 \mathrm{~L}$ atezolizumab + carboplatin/cisplatin + pemetrexed in stage IV non-squamous NSCLC. J Thorac Oncol. 2018;13(10 Suppl.):S332-3.

14. West $\mathrm{H}$, McLeod M, Hussein M, et al. Atezolizumab in combination with carboplatin plus nab-paclitaxel chemotherapy compared with chemotherapy alone as first-line treatment for metastatic non-squamous non-small-cell lung cancer for metastatic non-squamous non-small-cell lung can,
(IMpower130): a multicentre, randomised, open-label, phase 3 trial. Lancet Oncol. 2019:20:924-37.

15. Socinski MA, Jotte RM, Cappuzzo F, et al. Atezolizumab for first-line treatment of metastatic nonsquamous NSCLC N Eng J Med. 2018;378:2288-301.

16. Paz-Ares $L$, Luft $A$, Vicente $A$, et al. Pembrolizumab plus chemotherapy for squamous non-small-cell lung cancer. N Eng J Med. 2018;379:2040-51.

17. Jotte RM, Cappuzzo F, Vynnychenko I, et al. IMpower131: primary PFS and safety analysis of a randomized phase III study of atezolizumab + carboplatin + paclitaxel or nab-paclitaxel vs carboplatin + nab-paclitaxel as $1 \mathrm{~L}$ therapy in advanced squamous NSCLC. J Clin Oncol. 2018;36(18 Suppl.):LBA9000.
18. Ferrara R, Mezquita L, Texier M, et al. Hyperprogressive disease in patients with advanced non-small cell lung cancer treated with PD-1/PD-L1 inhibitors or with single agent chemotherapy. JAMA Oncol. 2018;4:1543-52.

19. Lo Russo G, Moro M, Sommariva M, et al. Antibody-FC/ FCR interaction on macrophages as a mechanism for hyperprogressive disease in non-small cell lung cancer subsequent to PD-1/PD-L1 blockade. Clin Cancer Res. 2019;25:989-99.

20. Kim Y, Kim CH, Kim HS, et al. Hyperprogression afte immunotherapy: clinical implication and genomic alterations in advanced non-small cell lung cancer patients (NSCLC). J Clin Oncol. 2018;36(18 Suppl.):9075.

21. Collazzo-Lorduy A, Galsky MD. Combining chemotherapy and immune checkpoint blockade. Curr Opin Urol 2016:26:508-13

22. Kepp O, Galluzzi L, Martins I, et al. Molecular determinants of immunogenic cell death, elicited by anticancer chemotherapy. Cancer Metastasis Rev. 2011;30:61-9.

23. Emens $L A$, Middleton $G$. The interplay of immunotherapy and chemotherapy: harnessing potential synergies. Cancer Immunol Res. 2015;3:436-43.

24. Lake RA, Robinson BW. Immunotherapy and chemotherapy - a practical partnership. Nat Rev Cancer. 2005:5:397-405.

25. Zitvogel L, Galluzzi L, Smyth MJ, Kroemer G. Mechanism of action of conventional and targeted anticancer therapies: reinstating immunosurveillance. Immunity. 2013;39:74-88.

26. Peng J, Hamanishi J, Matsumura N, et al. Chemotherapy induces programmed cell death-ligand 1 overexpression via the nuclear factor-кB to foster an immunosuppressive tumor microenvironment in ovarian cancer. Cancer Res. 2015;75:5034-45

27. Wang Z, Till B, Gao Q. Chemotherapeutic agent-mediated elimination of myeloid-derived suppressor cells. Oncoimmunology. 2017;6:e1331807.

28. Roselli M, Cereda V, di Bari MG, et al. Effects of conventiona therapeutic interventions on the number and function of therapeutic interventions on the number and function
regulatory T cells. Oncoimmunology. 2013;2:e277025.

29. Papadimitrakopoulou V Gadgeel SM, Borghaei $\mathrm{H}$, et al First-line carboplatin and pemetrexed (CP) with or without pembrolizumab (pembro) for advanced nonsquamous NSCLC updated results of KEYNOTE-021 cohort G. J Clin Oncol. 2017;35(15 Suppl.):9094.

30. Borghaei H, Langer CJ, Gadgeel S, et al. 24-month overal survival from KEYNOTE-021 cohort G: pemetrexed and carboplatin with or without pembrolizumab as first-line therapy for advanced nonsquamous non-small cell lung cancer. J Thorac Oncol. 2018:14:124-9.

31. Langer CJ, Gadgeel S, Borghaei H, et al. OA04.05 KEYNOTE-021: TMB and outcomes for carboplatin and pemetrexed with or without pembrolizumab for nonsquamous NSCLC. J Thorac Oncol. 2019;14(10 Suppl.): S216.

32. Garassino MC, Gadgeel S, Esteban E, et al. Absract CT043: Outcomes among patients (pts) with metastatic nonsquamous NSCLC with liver metastases or brain metastases treated with pembrolizumab plus pemetrexed-platinum: results from the KEYNOTE-189 study. Cancer Res. 2019;79(13 Suppl.):CT043.

33. Gadgeel S, Garassino MC, Esteban E, et al. KEYNOTE-189: Updated OS and progression after the next line of therapy (PFS2) with pembrolizumab (pembro) plus chemo with pemetrexed and platinum vs placebo plus chemo for metastatic nonsquamous NSCLC. J Clin Oncol. 2019;37(15 Suppl.):9013

34. Garassino MC, Rodriguez-Abreu D, Gadgeel S, et al. Evaluation of TMB in KEYNOTE-189: pembrolizumab plus chemotherapy v placebo plus chemotherapy for nonsquamous NSCLC.
J Thorac Oncol. 2019;14(10 Suppl.):S216-7.

35. Paz-Ares LG, Shen K, Higgs BW, et al. Association of liver metastases (LM) with survival in NSCLC treated with durvalumab (D) in two independent clinical trials. J Clin Oncol. 2017:35(15 Suppl):3038.

36. Pillai RN, Kamphorst AO, Owonikoko TK, et al. Liver metastases and sensitivity to checkpoint inhibitors in patients with non-small cell lung cancer (NSCLC). J Clin Oncol. 2016; 34(15 Suppl.): e20665)

37. Thein $\mathrm{K}$, Jahan $\mathrm{N}$, Tun $\mathrm{A}$, et al. MA03.07 First-line atezolizumab chemoimmunotherapy in advanced non-squamous NSCLC patients with EGFR/ALK genetic alterations. I Thorac Oncol. 2019;14(10 Suppl.):S259.

38. Jotte R, Cappuzzo F, Vynychenko I, et al. OA14.02 IMpower131: Final OS results of carboplatin + nab-paclitaxel \pm atezolizumab in advanced squamous NSCLC. J Thorac Oncol. 2019;14 (10 Suppl.):S243-44.

39. Borghaei $\mathrm{H}$, Langer $\mathrm{C}$, Paz-Ares $\mathrm{L}$, et al. MA25.01 Pembrolizumab plus chemotherapy for advanced NSCLC without tumor PD-L1 expression: pooled analysis of KNO21G KN189 and KN407. I Thorac Oncol. 2019;14(10 Suppl):S350.

10. Ahn MJ, Yang J, Yu H, et al. 1360: Osimertinib combined with durvalumab in EGFR-mutant non-small cell lung cancer: results from the TATTON phase Ib trial. I Thorac Oncol. 2016;11 (4 Suppl.):S115.

41. Gettinger S, Hellmann MD, Chow LQM, et al. Nivolumab plus erlotinib in patients with EGFR-mutant advanced NSCLC J Thorac Oncol. 2018;13:1363-72.

42. Ma BBY, Rudin CM, Cervantes A, et al. Abstract 1017 . Preliminary safety and clinical activity of erlotinib plus atezolizumab from a phase Ib study in advanced NSCLC. Ann Oncol. 2016:27(Suppl. 9):ix139-56.

43. Gibbons DL, Chow LQ, Kim Dw, et al. 570 Efficacy, safety and tolerability of MEDI4736 (durvalumab [D]), a human IgG1 antiprogrammed cell death-ligand-1 (PD-L1) antibody, IgG1 antiprogrammed cell death-ligand-1 (PD-L1) antibody,
combined with gefitinib (G): a phase I expansion in TKI-naïve combined with gefitinib (G): a phase l expansion in TKI-n
patients (pts) with EGFR mutant NSCLC. J Thorac Oncol. 2016;11(Suppl. 4):S79.

44. Spigel DR, Reynolds C, Waterhouse D. Phase $1 / 2$ study of the safety and tolerability of nivolumab plus crizotinib for the first-line treatment of anaplastic lymphoma kinase translocation - positive advanced non-small cell lung cancer (CheckMate 370). J Thorac Oncol. 2018;13:682-8.

45. Felip E, de Braud FGD, Maur M. Ceritinib plus nivolumab (NIVO) in patients (pts) with anaplastic lymphoma kinase positive (ALK+) advanced non-small cell lung cancer (NSCLC). J Clin Oncol. 2017;35(Suppl. 15):2502.

46. Kim DW, Gadgeel SM, Gettinger SN, et al. Safety and clinica activity results from a phase $\mathrm{Ib}$ study of alectinib plus atezolizumab in ALK+ advanced NSCLC (aNSCLC). I Clin Oncol. 2018;36(Suppl. 15):9009.

47. Shaw AT, Lee S-H, Ramalingham SS. Avelumab (anti PD-L1) in combination with crizotinib or lorlatinib in patients with previously treated advanced NSCLC. phase ib results from JAVELIN Lung 101. J Clin Oncol. 2018;36(Suppl. 15):9008.

48. Hellmann MD, Rizvi NA, Goldam JW, et al. Nivolumab plus ipilimumab as first-line treatment for advanced non-small-cell lung cancer (CheckMate 012): results of an open-label, phase I, multicohort study. Lancet Oncol. 2017;18:31-41.

49. Hellmann MD, Ciuleanu TE, Pluzanski A, et al. Nivolumab plus ipilimumab in lung cancer with a high tumor mutational burden. N Eng J Med. 2018;378:2093-104.

50. Hellmann MD, Paz-Ares L, Bernabe Caro L, et al. Nivolumab plus ipilimumab in advanced non-smal cell lung cancer. N Engl J Med. 2019;381:2020-31. 